\title{
Doxycycline induces SLT2 phosphorylation in Candida glabrata
}

Hala Almshawit* and Ian Macreadie

School of Applied Sciences, RMIT University, 124 La Trobe St, Melbourne VIC 3000, Australia

\section{Publication History:}

Received: March 08, 2017

Accepted: June 25, 2017

Published: June 27, 2017

\section{Keywords:}

Levofloxacin, Chitosan, EDTA, S. aureus, MRSA, Antibiotic resistance, Antimicrobial study

\section{Introduction}

Various factors including the increased numbers of immunocompromised patients (e.g. AIDS and cancer patients), a growing aged population, the increased use of indwelling medical devices and antibiotic misuse have led to the increase in Candida infection incidence. C. glabrata is one of non - C. albicans species which has become of concern because of its increased incidence and ability to develop resistance towards common antifungals [1].

Detailed genetic studiesof C. glabrata are now commonplace thanks to the regulatable promoters which are available to the researchers to induce or repress gene expression in C. glabrata. These promoters, such as tetO, MET3 and $P D C 1$ promoters [2,3] control expression of the gene of interest upon incubation of cells in growth media containing the activating or the repressing substance. The tetregulatable promoteris directed affected by tetracycline,induced by addition of doxycycline to the growth medium with induction being reversed by doxycycline removal. This system has been successfully used forfunctional analysis studies of essential genes with unknown function in C. glabrata [2]. Doxycycline was described to have no detectable effect on global gene expression in Saccharomyces cerevisiae at certain concentration [4]. However, there are no studies that examine the effect of doxycycline on C. glabrata global gene expression.

In mammalian cells doxycycline was shown to be an ERK1/2 inhibitor [5]. Abioinformatic database analysis (Candida Genome Database (CGD)) indicates that Homo sapiens ERK2 shows $48 \%$ identity and 65\% similarity to the C. glabrata SLT2, the MAPKKKK protein of cell wall integrity mitogen activated protein kinase signaling pathway (CWI MAPK). Based on that, we set out to determine the effect of doxycycline on SLT2 phosphorylation status in C. glabrata and onits survival in general. We believe that research community in the field of yeast molecular genetics may benefit from the conclusions of our studies.

\section{Materials and Methods}

\section{Susceptibility of C. glabrata to doxycycline}

C. glabrata ATCC90030 and C. glabrata ATCC2001 strainswere used in this study. Susceptibility testing to doxycycline was performed using three methods. The first method was the standardized broth microdilution assay as defined by CLSI (2008) using RPMI1640 medium (Sigma) and C. glabrata ATCC2001. Doxycycline concentrations ranged from 6.2 to $200 \mu \mathrm{g} / \mathrm{ml}$. After incubation for $24 \mathrm{~h}$ at $35^{\circ} \mathrm{C}$ the minimum inhibitory concentration was determined visually. Susceptibility was also observed by spotting $5 \mu$ from serial dilutions of both strains onto YEPD agar plates $[1 \%(\mathrm{w} / \mathrm{v})$ yeast extract, $2 \%(\mathrm{w} / \mathrm{v})$ bacteriological peptone, $2 \%(\mathrm{w} / \mathrm{v})$ dextrose and $1.5 \%$ bacteriological agar (Oxoid)] contain 100 or $200 \mu \mathrm{g} / \mathrm{ml}$ doxycycline.

Thesensitivity of C. glabrata to doxycycline was tested in water as well. High density cells in water (about 3-8 x 106CFU/ml) were treated with different concentrations of doxycycline ranging from 0 to $400 \mu \mathrm{g} / \mathrm{ml}$. Preparation of C. glabrata cells for doxycycline treatment in water was carried out as described previously in [6]. Doxycycline was dissolved in RPMI1640 medium or added directly to water.

To examine the effect of sorbitol and antioxidants such as ascorbic acid and reduced glutathione on inhibition of $50 \mu \mathrm{g} / \mathrm{mlof}$ doxycycline toxicity in water, $1 \mathrm{M}$ of sorbitol or $10 \mathrm{mM}$ of ascorbic acid or reduced glutathione were added to about $3 \times 105 \mathrm{CFU} / \mathrm{ml}$ of C. glabrata ATCC90030 together with doxycycline.

\section{Susceptibility of C. glabrata to doxycycline}

Detection of SLT2 phosphorylation by using of flow cytometry was carried out using phospho-p44/42 MAPK (Erk1/2) (Thr202/Tyr204) antibody (Cell Signaling Technology). Cells of C. glabrata ATCC2001 from an overnight YEPD plate were used to inoculate YEPD liquid medium and incubated $4-5 \mathrm{~h}$ at $30^{\circ} \mathrm{C}$ with agitation $(200 \mathrm{rpm})$. Cells were harvested and washed with RPMI1640 liquid medium and resuspended in the same medium at density of about $\mathrm{OD}_{600}=1$.

To examine SLT2 phosphorylation induction by doxycycline, $C$. glabrata ATCC2001 exponential phase cultures were examined $30 \mathrm{~min}$

"Corresponding Author: Dr. Hala Almshawit, School of Applied Sciences, RMIT University, 124 La Trobe St, Melbourne VIC 3000, Australia; E-mail: hala.almshawit@gmail.com

Citation: Almshawit H, Macreadie I (2017) Doxycycline induces SLT2 phosphorylation in Candida glabrata. Int J Clin Med Microbiol 2: 122. doi: https:// doi.org/10.15344/2456-4028/2017/122

Copyright: (C 2017 Almshawit et al. This is an open-access article distributed under the terms of the Creative Commons Attribution License, which permits unrestricted use, distribution, and reproduction in any medium, provided the original author and source are credited. 
after addition of 0,25 or $50 \mu \mathrm{g} / \mathrm{ml}$ doxycycline. Cells were fixed, permeabilised and antigens detected according to the primary antibody manufacturer's instructions. In brief, one ml samples were collected from each treatment and $100 \mu \mathrm{l}$ of $37 \%$ formaldehyde was added. The samples were incubated at $37^{\circ} \mathrm{C}$ for $10 \mathrm{~min}$, chilled on ice for $1 \mathrm{~min}$ and centrifuged $(9000 \mathrm{rpm})$ for $1 \mathrm{~min}$. The pellets were resuspended in $100 \mu \mathrm{l}$ PBS. Permeabilisation was carried out by adding $900 \mu \mathrm{l}$ of $100 \%$ cold methanol $\left(-20^{\circ} \mathrm{C}\right)$ and incubated on ice for $30 \mathrm{~min}$. For immunostaining, cells were harvested and washed with PBS. Pellets were resuspended in blocking buffer by vortexing and incubated for $10 \mathrm{~min}$ at room temperature. Then the cells were harvested and resuspended in blocking buffer containing 1:200 diluted phospho-p44/42 MAPK primary antibody(thr202/tyr204; Cell Signaling Technology \#9101). Cells were incubated for $1 \mathrm{~h}$ at room temperature. After washing with PBS the cells were suspended in 1:1000 diluted anti-rabbit HRP secondary antibody (Sapphire, Australia) in blocking buffer and incubated for $30 \mathrm{~min}$ in the dark at room temperature. After three washes with PBS, fluorescence intensity was detected by AmCyan filter in FACS Canto II (BD Biosciences) flow cytometer.

\section{Results}

\section{Susceptibility of C. glabrata to doxycycline in media}

The minimum inhibitory concentration of doxycycline to C. glabrata ATCC2001 in RPMI1640 medium was $200 \mu \mathrm{g} / \mathrm{ml}$. A weak growth was visualized in the microwells which contained $100 \mu \mathrm{g} / \mathrm{ml}$ doxycycline comparing with growth control microwells.Aliquotesof serial dilutions of both strains on YEPD agar containing 0, 100 or 200 $\mu \mathrm{g} / \mathrm{ml}$ doxycycline showed no inhibition of growth (Figure 1 ).
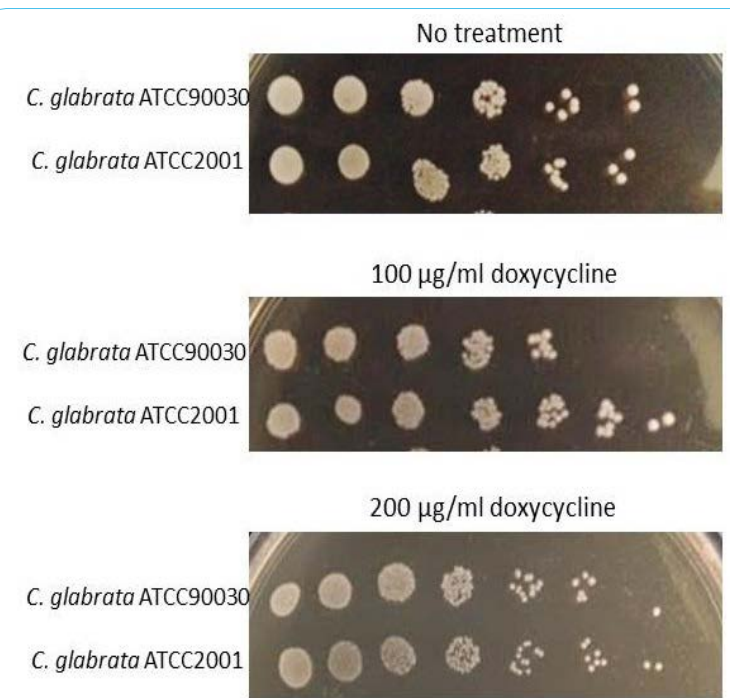

Figure 1: Susceptibility of C. glabrataATCC2001 to doxycycline by spotting serial dilutions of C. glabrata ATCC2001 and ATCC90030 on YEPD agar plates contain 0,100 or $200 \mu \mathrm{g} / \mathrm{ml}$ doxycycline.

\section{Susceptibility of C. glabrata to doxycycline in media}

C. glabrata high density cellpopulations $\left(\sim 3 \times 10^{6} \mathrm{CFU} / \mathrm{ml}\right)$ of ATCC 90030 strain or $8 \times 106 \mathrm{CFU} / \mathrm{ml}$ of ATCC2001 strain in water began to lose more than 60 and $80 \%$ of their viability respectively after treatment with $40 \mu \mathrm{g} / \mathrm{ml}$ or $50 \mu \mathrm{g} / \mathrm{ml}$ of doxycycline (Figure $2 \mathrm{a}$ and Figure $2 \mathrm{~b}$ ). The toxicity of doxycycline in water could be partly abrogated (20\% loss in viability) by adding $10 \mathrm{mM}$ ascorbic acid but not reduced glutathione ( $>80 \%$ loss in viability). Sorbitol also could not save cells from doxycycline toxicity in water (Figure 2c).
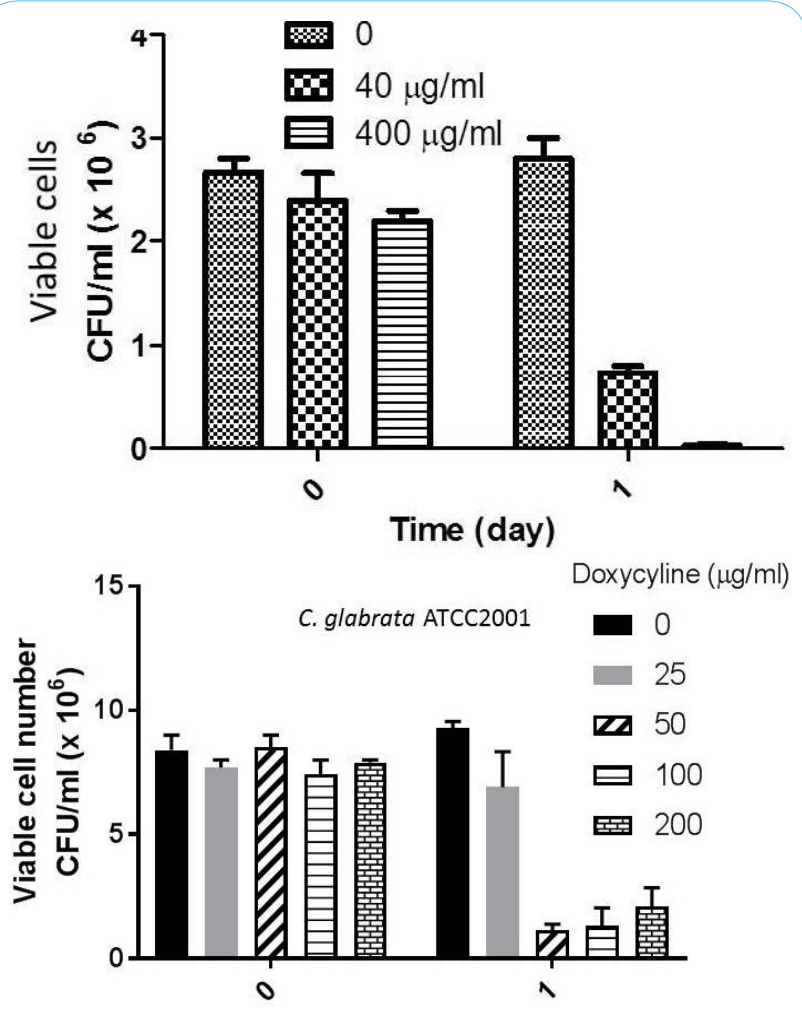

Time (day)

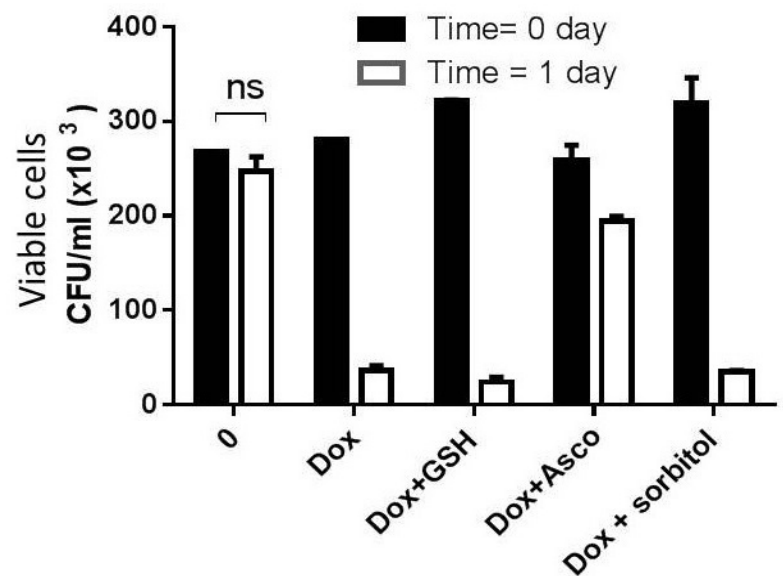

Figure 2: Susceptibility of C. glabrata to doxycycline in water (A) C. glabrata ATCC90030 (B) C. glabrata ATCC2001) (C) protection of C. glabrata ATCC 90030 cells against the toxicity of $50 \mu \mathrm{g} / \mathrm{ml}$ doxycycline in water using $1 \mathrm{M}$ sorbitol, $10 \mathrm{mM}$ of ascorbic acid (Asco) or reduced glutathione $(\mathrm{GSH}), \mathrm{ns}=$ not significant.

\section{Doxycycline induces SLT2 phosphorylation}

Experiments were designed to find whether doxycycline may act as SLT2 inhibitor, and toxicity of doxycycline in water was due to this property. Cells in RPMI1640 were treated with doxycycline and examined for SLT2 phosphorylation. Concentrations of 25, 50 and $100 \mu \mathrm{g} / \mathrm{ml}$ of doxycycline were tested for their ability to inhibit SLT2 phosphorylation. The phosphorylation of SLT2 in C. glabrata ATCC2001 was measured using flow cytometry. Within $30 \mathrm{~min}$ of incubation in the lowest concentration of doxycycline $(25 \mu \mathrm{g} / \mathrm{ml})$, phosphorylation of SLT2 protein was detected. The phosphorylation was higher in the cells treated with $50 \mu \mathrm{g} / \mathrm{ml}$ of doxycycline, whereas 
untreated cells showed no detectable positive events indicating no SLT2 phosphorylation in these cells (Figure 3).

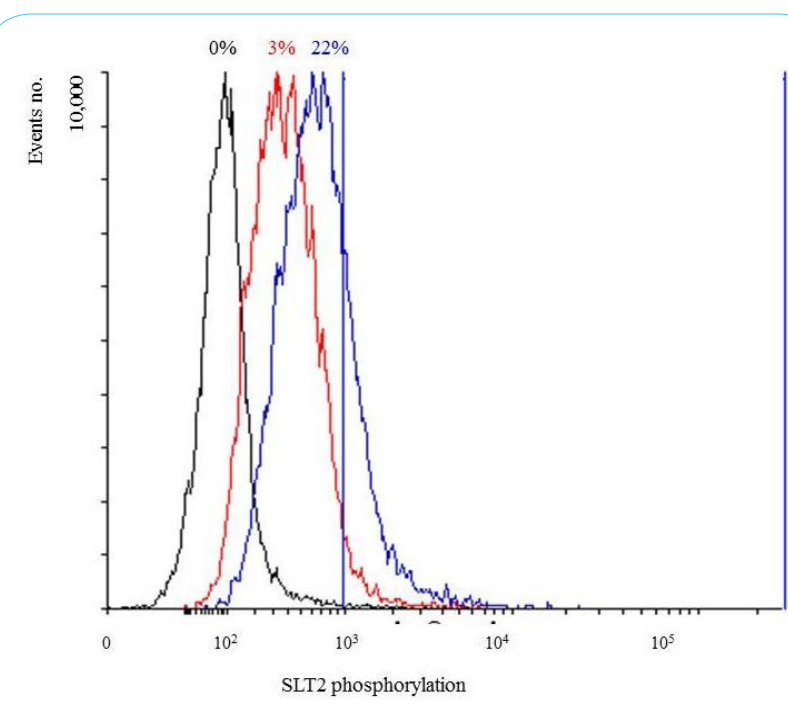

Figure 3: Doxycycline induces SLT2 phosphorylation. C. glabrata ATCC2001 cells growing exponentially were treated with $25 \mu \mathrm{g} / \mathrm{ml}$ doxycycline (red) and $50 \mu \mathrm{g} / \mathrm{ml}$ DOX (blue) after $30 \mathrm{~min}$ in media. Black is untreated cells. The percentages indicate the fluorescence intensity.

\section{Discussion}

Doxycycline concentrations of $200 \mu \mathrm{g} / \mathrm{ml}$ inhibited C. glabrata ATCC2001 growth in the MIC assay, while a concentration of one fifth of the MIC of doxycycline was enough to cause loss in viability of this fungus in water. In our previous study $>10^{4} \mathrm{CFU} / \mathrm{ml}$ of C. glabarat was shown to be able to keep their viability in water over at least three days [6]. This fact has been shown again in this work as $8 \times 10^{6} \mathrm{CFU} /$ $\mathrm{ml}$ of C. glabarat ATCC2001and $3 \times 10^{5}$ of C. glabrata ATCC 90030 were able to maintain their viability in water.

Many studies depend on spotting serial dilution of yeast on YEPD agar plates to examine the effect of doxycycline on promoter induction [7] or synergy with other compounds [8]. Therefore, the spotting assay was carried out in this study to observe the effect of $100-200 \mu \mathrm{g} / \mathrm{ml}$ of doxycycline on C. glabrata reference strains. Both strains were not sensitive to the highest concentration of doxycycline. However, other yeast species such as C. albicans was susceptible to doxycycline at 200 $\mu \mathrm{g} / \mathrm{ml}[8]$ when it was tested by using the spotting assay. A study on S. cerevisiae cells treated with $40 \mu \mathrm{g} / \mathrm{ml}$ of doxycycline showed that there was no phenotypic effect and no significant effect on their global genome transcription levels which allow the use of tet $O$ regulatable promoter system for genetic studies [4]. In our study it is clear that $200 \mu \mathrm{g} / \mathrm{ml}$ of doxycycline in YEPD agar plates did not cause any phenotypic effect on C. glabrata in media but this was not the case when this species was treated with doxycycline in water. It seems that yeast species vary in their response to doxycycline treatment as Fiori et al.,[8] demonstrated by the difference between $C$. albicans and $S$. cerevisiae to doxycycline and fluconazole treatment combinations. Growth in the presence of fluconazole and doxycycline was restored by overexpression of ERG11 in S. cerevisiae but not in C. albicans [8].

Since CWIMAPK signaling has been reported to be activated in hypo-osmotic conditions [9] and doxycycline was described as an ERK1/2 inhibitor [5], the homolog of SLT2 in C. glabrata (CGD), the question was asked, could this antibiotic act as a SLT2 inhibitor, leading to cell death in water? The toxicity of doxycycline in water was not abrogated by adding the osmo-stabiliser "sorbitol". In contrast, staurosporine (a known PKC1 inhibitor) toxicity in water could be abrogated by sorbitol [10]. PKC1 is an upstream kinase of the CWIMAPK signaling pathway. This indicates doxycycline has a target other than CWI-MAPK. Flow cytometry analysis of SLT2 phosphorylation confirmed that doxycycline does not inhibit SLT2 phosphorylation: indeed doxycycline activates SLT2 phosphorylation. The activation of this protein occurred once C. glabrata cells were treated with sub-inhibitory concentrations of doxycycline $(50 \mu \mathrm{g} / \mathrm{ml})$ in RPMI1640 medium.

In summary, the fungicidal effect of doxycycline in water is not due to inhibition of the SLT2 activation. Doxycycline is an iron chelator leading to depletion of intracellular iron [8]. Iron depletion has been proposed to decrease ergosterol content in C. albicans and $S$. cerevisiae, leading to higher fluidity in cell membranes, with consequent increased passive diffusion $[11,12]$. Further investigation might include the examination of the effect of iron addition on C. glabrata sensitivity to doxycycline. Water and doxycycline might diffuse passively and cause cell death. The elimination of doxycycline toxicity with ascorbic acid might indicate an interference with the oxidative homeostasis due to iron depletion. In addition, doxycycline was shown to increase the susceptibility of C. albicans to amphotericin when they were treated with 50 to $200 \mu \mathrm{g} / \mathrm{ml}$ of doxycycline [13]. This alteration in susceptibility was suggested to be due to the inhibition of mitochondrial function in C. albicans, which eliminates the diauxic shift [13]. Lack of diauxic shift, or the lack of functional mitochondria alters sterol metabolism, resulting in lower ergosterol levels, consistent with the need for 12 molecules of oxygen to synthesize one molecule of ergosterol [13]. Saccharomyces cerevisiae was shown to require antioxidant function to resist the toxicity of doxycycline [14]: this has been also demonstrated in our study where ascorbic acidprotected against doxycycline toxicity in water. However, it is not clear for us why reduced glutathione, also an antioxidant, did not protect against doxycycline toxicity.

In conclusion this study demonstrates that C. glabratacells are more sensitive to doxycycline in water than in media, and doxycycline isan inducer of SLT2 phosphorylation. Furthermore, this study supports the proposed mechanism of killing of doxycycline in water may be attributed to an alteration of oxidative homeostasis in yeast which alters the cells permeability.

\section{Competing Interests}

The authors declares that they have no competing interests.

\section{References}

1. Silva S, Negri M, Henriques M, Oliveira R, Williams DW, et al. (2012) Candida glabrata, Candida parapsilosis and Candida tropicalis: biology, epidemiology, pathogenicity and antifungal resistance. FEMS Microbiol Rev 36: 288-305

2. Nakayama H, Izuta M, Nagahashi S, Sihta EY, Sato Y, et al. (1998) A controllable gene-expression system for the pathogenic fungus Candida glabrata. Microbiol 144: 2407-2415.

3. Zordan RE, Ren Y, Pan SJ, Rotondo G, De Las Penas A, et al. (2013) Expression plasmids for use in Candida glabrata. G3 (Bethesda) 3: 16751686.

4. Wishart JA, Hayes A, Wardleworth L, Zhang N, Oliver SG (2005) Doxycycline, the drug used to control the tet-regulatable promoter system, has no effect on global gene expression in Saccharomyces cerevisiae. Yeast 22: 565-569. 
Citation: Almshawit H, Macreadie I (2017) Doxycycline induces SLT2 phosphorylation in Candida glabrata. Int J Clin Med Microbiol 2: 122. doi: https://doi. org/10.15344/2456-4028/2017/122

Page 4 of 4

5. Kim HS, Luo L, Pflugfelder SC, Li DQ (2005) Doxycycline inhibits TGFbeta1-induced MMP-9 via Smad and MAPK pathways in human cornea epithelial cells. Invest Ophthalmol Vis Sci 46: 840-848.

6. Almshawit H, Pouniotis D, Macreadie I (2014) Cell density impacts on Candida glabrata survival in hypo-osmotic stress. FEMS Yeast Res 14 508-516.

7. Matsuo Y, Granneman S, Thoms M, Manikas RG, Tollevery D, et al. (2014) Coupled GTPase and remodelling ATPase activities form a checkpoint for ribosome export. Nat 505:112-116.

8. Fiori A, Van Dijck P (2012) Potent synergistic effect of doxycycline with fluconazole against Candida albicans is mediated by interference with iron homeostasis. Antimicrob Agents Chemother 56: 3785-3796.

9. Levin DE (2005) Cell Wall Integrity Signaling in Saccharomyces cerevisiae. Microbiol Mol Biol Rev 69: 262-291.

10. Almshawit $\mathrm{H}$ (2016) Studies on the effect of thymoquinone on oxidative stress and cell wall integrity of Candida glabrata, PhD thesis, pp. 135.

11. Prasad T, Chandra A, Mukhopadhyay CK, Prasad R (2006) Unexpected link between iron and drug resistance of Candida spp.: iron depletion enhances membrane fluidity and drug diffusion, leading to drug-susceptible cells. Antimicrob Agents Chemother 50: 3597-606.

12. Shakoury-Elizeh M, Protchenko O, Berger A, Cox J, Gable K, et al. (2010) Metabolic response to iron deficiency in Saccharomyces cerevisiae.J Bio Chem 285: 14823-14833.

13. Oliver BG, Silver PM, Marie C, Hoot SJ, Leyde SE, White TC (2008) Tetracycline alters drug susceptibility in Candida albicans and other pathogenic fungi. Microbiol, 154: 960-970.

14. Angrave FE, Avery SV (2001) Antioxidant functions required for insusceptibility of Saccharomyces cerevisiae to tetracycline antibiotics. Antimicrob Agents Chemother 45: 2939-2942. 